\title{
Results Regarding Control of Species Monathropalpus buxi Geoff by Capturing Adults with Colored Traps
}

\author{
Crisitina SOPORAN ${ }^{1}$, Ion OLTEAN ${ }^{1}$, Vasile FLORIAN ${ }^{1}$, Teodora FLORIAN ${ }^{1 *}$ \\ ${ }^{1}$ Department Environment and Plant Protection. University of Agricultural Sciences and Veterinary \\ Medicine Faculty of Agriculture \\ * corresponding author: florian.teodora@yahoo.com \\ Bulletin USAMV series Agriculture 72(1)/2015 \\ Print ISSN 1843-5246; Electronic ISSN 1843-5386 \\ DOI 10.15835/buasvmcn-agr: 11170
}

\begin{abstract}
To control Monarthorpalpus buxi Geoff. species, the main pest of Buxus plants, in addition to chemical treatments an alternative method can be used for mass capture of adults with colored panels. In the area of Cluj-Napoca, in 2012-2013 was tested the effectiveness of this method. In this experiment was tested efficacy of white, blue, yellow and green panels. Of the 39603 adults captured during the two years, $36.4 \%$ were on green panels; $33.7 \%$ were on yellow panels; $24.1 \%$ were on white panels; $5.8 \%$ were on blue panels. Compared to the version where we did not apply any method of control, mass capture of Monarthropalpus buxi Geoff. adults with colored panels, attack frequency decreased at a rate of about 88\% in 2012 (frequency of infested leaves was 8.61\% compared to 70.78\% in control variant) and $90 \%$ in 2013 (frequency of infested leaves was $7.67 \%$ compared to $77.36 \%$ in control variant).
\end{abstract}

Keywords: mass capturing, Monarthropalpus buxi Geoff., traps

\section{INTRODUCTION}

Monarthorpalpus buxi Rubs. is a monophagus species speread all over the continent (Skuhravá, 2005).. The larvae feed exclusively on the leaves of: Buxus sempervirens L., Buxus roduntifolia, Buxus bullata, Buxus nana, Buxus balearica (Brewer et al., 1984; Hrubik et al., 1998; Vamvakas et al., 2006). Attacked parts in the form of swelling on the underside of leaves of cranberry in autumn became yellow, then brown, dry totally or partially dried and give an unsightly appearance of the plant (Vamvakas et al., 2006). On a strong attack can be dried whole branches or the entire plant (Batdorf, 1994; Bena et al., 1996; Eustachio and Raupp, 2001).

Control of this specie can be achieved only through the rational application of a whole complex of measures. You can use the methods like: physical, mechanical, biological, biotechnical and chemical. Mechanical methods of control consist in collect of insects and larvae directly or by isolating them in different ways. On the basis of these methods lies knowledge of morphological, biological and behavioral needs of the species. Because this species show a positive phototropism to a specific wavelength to control them it can by use colored adhesive panels. The method is very efficient small areas.

\section{AIMS}

Using colored traps in fight against Monarthropalpus buxi Geoff.

\section{MATERIALS AND METHODS}

During the experimental period was check the preference of species studied for colors: white, yellow, blue and green. For this purpose, during the flight of adults were placed colored glued traps 
over Buxus senpenvirens bushes at a distance of $0.55 \mathrm{~cm}$ between them at three different heights: $0 \mathrm{~cm}$ (at the plant); $0.50 \mathrm{~cm} ; 1 \mathrm{~m}$.

In these locations we checked the frequency of leaves attacked by larvae of Monarthropalpus buxi Geoff. species. We did check it at the end of August and compared it with the frequency of attacked leaves of Buxus bushes that did not apply any control measures.

To determine the frequency of attack of Monarthropalpus buxi Geoff. species were cut with scissors 30 branches from Buxus senpenvirens plants studied, from the top, bottom and middle of the plant. Branches placed in plastic wrap were taken to the laboratory for analysis. Each branch was taken separately and were counted infested leaves and healthy leaves to be able to determine the frequency of attacks.

\section{RESULTS AND DISCUSSION}

Table 1 show the frequency of attack produced by Monarthropalpus Buxi in the 30 samples collected branches in the two experimental years from the plants which did not apply to any method of control.

In 2012 on the 30 samples of branches were analyzed a number of 1749 leaves. $70.78 \%$ of the analyzed leaves were attacked. On samples, attack frequency of Monarthropalpus buxi Geoff. ranged from 43.33\% (sample no. 25) and 97\% (sample no. 28). In seven samples attack rate was over $90 \%$, on three samples attack rate was between 80-90\%, on the eight samples attack rate was between 70 $80 \%$, and in 12 samples was below average attack frequency from all samples analyzed.

In the year 2013 on the 30 samples that were analyzed it was registred a number of 2085 leaves. This year on the whole plant material examined, attack rate was $77.36 \%$, so compare to the previous year was reported an increase in this parameter by 6.58 percentage points. 2013 was a year of very favorable conditin for the growth and development of this pest. The lowest frequency of attack (54.84\%) as recorded on the sample no. 27 , and the maximum frequency of the attack was in sample No. 7, (93.85\%). In 5 samples attack rate was over $90 \%$ in 10 samples attack frequency was between $80-90 \%$ in 7 samples attack rate was between $70-80 \%$, and in 8 samples was below average attack frequency from all samples analyzed.
Using colorful panels in 2012 were captured 21573 adults, being the year that was achieved the highest number of catches in the two experimental years (Table. 2). Most captures were made by yellow panels that captured 7467 adults, representing $34.5 \%$ of the total catch. Green panels have made 7233 captures (representing 33.4\% of total catch), white panels have made 5785 captures (representing $26.7 \%$ of total catch) and the blue one captured 1178 adults (representing $5.4 \%$ of the total catch).

In 2013 with colored panels were captured 18030 adults. Compare to the previous year the total number of captures was lower by 3543 adults. Most captures were on green panels that captured 7196 adults, representing 39.9\% of the total catch. Yellow panels captured 5846 adults, representing $32.4 \%$ of the total catch. White panels have made 3766 captures (representing 20.9\% of total catch) and the blue one captured 1222 adults (representing $6.8 \%$ of total catch).

Table 3 presents statistical processing of catches by the 4 color panels used during the two experimental years. By far, green and yellow panels gave the best results, followed by white traps. Results are statistically assured.

Table 4 presents the situation of attack frequency on leaves in two experimental years on the 30 branches harvested from the variant that was done the mass capture the adults with colored panels.

In 2012, on the 30 analyzed branches were numbered 2080 leaves, returning an average of 69 leaves / branches. On the analyzed branches, the average frequency of infested leaves was 8.61\%. On Buxus bushes where they not proceeded to any control metods, frequency of infested leaves was $70.78 \%$. By capturing adults with colored panels, attack frequency was reduced by $87.84 \%$. Maximum frequency of attack on analyzed branches was $17.50 \%$ (branch no. 12) and branches no. 19 and 29 no leaves with atack were noted.

In this experimental group were reported two branches with more than $15 \%$ attack rate, attack rate on 11 branches was between $10-15 \%$, on 9 branches attack frequency was between 5-10\% and on 8 branches rate was below $5 \%$.

In 2013 from the 30 branches was analyze a number of 2321 leaves, returning an average of 77 leaves / branches. 
This year on the whole plant material examined, the average frequency of attacks was $7.67 \%$, which means a decrease of $90.08 \%$ compared to the attack frequency of the variant without a method of control where the attack frequency was $77.36 \%$. This year on the variant where we captured adults with coloured panels; attack frequency was slightly lower compared to the previous year. Data from this year, in conjunction with data from the previous year, demonstrating efficacy glue colored panels in control this pest.

Maximum frequency of infested leaves from the analyzed branches was $17.05 \%$ (branch no. 26) and on branches no. 17, 24 and 27 were not reported attacked leaves. In this experimental group were reported five branches with more than $15 \%$ attack rate; attack rate on 4 branches was

Tab. 1. The attack frequency of the Monarthropalpus buxi Geoff. species on Buxus sempervirens L. (untreated control, Cluj-Napoca, 2012, 2013)

\begin{tabular}{|c|c|c|c|c|c|c|c|c|}
\hline \multirow{3}{*}{ Sample } & \multirow{2}{*}{\multicolumn{2}{|c|}{ Leaves analysed/plant }} & \multicolumn{4}{|c|}{ Out of which: } & \multirow{2}{*}{\multicolumn{2}{|c|}{ Attack frequency $\%$}} \\
\hline & & & \multicolumn{2}{|c|}{ Healthy leaves } & \multicolumn{2}{|c|}{ Attacked leaves } & & \\
\hline & 2012 & 2013 & 2012 & 2013 & 2012 & 2013 & 2012 & 2013 \\
\hline 1 & 51 & 83 & 2 & 5 & 49 & 78 & 95.45 & 93,97 \\
\hline 2 & 151 & 71 & 66 & 7 & 85 & 64 & 56.29 & 90,14 \\
\hline 3 & 13 & 52 & 5 & 4 & 8 & 48 & 61.53 & 92,31 \\
\hline 4 & 68 & 79 & 9 & 11 & 59 & 68 & 86.76 & 86,07 \\
\hline 5 & 22 & 43 & 1 & 12 & 21 & 31 & 95.45 & 72,09 \\
\hline 6 & 101 & 95 & 31 & 25 & 70 & 70 & 69.30 & 73,68 \\
\hline 7 & 11 & 65 & 1 & 4 & 10 & 61 & 90.90 & 93,85 \\
\hline 8 & 31 & 39 & 3 & 5 & 28 & 34 & 90.32 & 87,18 \\
\hline 9 & 48 & 103 & 8 & 27 & 40 & 76 & 83.33 & 73,79 \\
\hline 10 & 66 & 73 & 15 & 9 & 51 & 64 & 77.27 & 87,67 \\
\hline 11 & 44 & 89 & 17 & 23 & 27 & 66 & 61.36 & 74,16 \\
\hline 12 & 100 & 78 & 56 & 11 & 44 & 67 & 44,00 & 85,90 \\
\hline 13 & 76 & 112 & 16 & 32 & 60 & 80 & 78.94 & 71,43 \\
\hline 14 & 23 & 74 & 3 & 17 & 20 & 57 & 86.95 & 77,02 \\
\hline 15 & 130 & 63 & 56 & 24 & 74 & 39 & 56.92 & 61,90 \\
\hline 16 & 44 & 39 & 12 & 7 & 32 & 32 & 72.72 & 82,05 \\
\hline 17 & 32 & 82 & 16 & 29 & 16 & 53 & 50,00 & 64,63 \\
\hline 18 & 15 & 34 & 1 & 5 & 14 & 29 & 93.33 & 85,30 \\
\hline 19 & 41 & 49 & 16 & 21 & 25 & 28 & 60.97 & 57,14 \\
\hline 20 & 54 & 29 & 5 & 4 & 49 & 25 & 90.74 & 86,21 \\
\hline 21 & 75 & 67 & 21 & 22 & 54 & 45 & 72,00 & 67,16 \\
\hline 22 & 83 & 98 & 18 & 35 & 65 & 63 & 78.31 & 64,29 \\
\hline 23 & 53 & 37 & 20 & 8 & 33 & 29 & 62.26 & 78,38 \\
\hline 24 & 49 & 65 & 16 & 24 & 33 & 41 & 67.34 & 63,08 \\
\hline 25 & 60 & 86 & 34 & 29 & 26 & 57 & 43.33 & 66,28 \\
\hline 26 & 45 & 59 & 11 & 9 & 34 & 50 & 75.55 & 84,74 \\
\hline 27 & 58 & 62 & 19 & 28 & 39 & 34 & 67.24 & 54,84 \\
\hline 28 & 68 & 53 & 2 & 4 & 66 & 49 & 97,00 & 92,46 \\
\hline 29 & 65 & 127 & 15 & 22 & 50 & 105 & 76.92 & 82,68 \\
\hline 30 & 72 & 79 & 16 & 9 & 56 & 70 & 77.77 & 88,61 \\
\hline Total & 1749 & 2085 & 511 & 472 & 1238 & 1613 & 70.78 & 77,36 \\
\hline
\end{tabular}


Tab. 2. Monarthropalpus buxi Geoff. captures made on coloured panels (Cluj-Napoca, 2012 - 2013)

\begin{tabular}{ccccccccccc}
\hline \multirow{2}{*}{ Date } & \multicolumn{1}{c}{ White panels } & \multicolumn{2}{c}{ Blue panels } & \multicolumn{2}{c}{ Yellow panels } & \multicolumn{2}{c}{ Green panels } & \multicolumn{2}{c}{ Total no. of captures } \\
\cline { 2 - 13 } & 2012 & 2013 & 2012 & 2013 & 2012 & 2013 & 2012 & 2013 & 2012 & 2013 \\
\hline 01.05. & 0 & 0 & 0 & 0 & 0 & 0 & 0 & 0 & 0 & 0 \\
\hline 02.05. & 0 & 0 & 0 & 0 & 0 & 0 & 0 & 0 & 0 & 0 \\
\hline 03.05. & 2 & 13 & 0 & 3 & 0 & 37 & 3 & 30 & 5 & 83 \\
\hline 04.05. & 22 & 345 & 0 & 107 & 8 & 847 & 43 & 1836 & 73 & 3135 \\
\hline 05.05. & 85 & 1000 & 2 & 264 & 69 & 1631 & 217 & 1799 & 373 & 4694 \\
\hline 06.05. & 307 & 1076 & 13 & 451 & 417 & 2024 & 379 & 2216 & 1116 & 5767 \\
\hline 07.05. & 590 & 787 & 82 & 295 & 578 & 917 & 710 & 892 & 1960 & 2891 \\
\hline 08.05. & 959 & 450 & 90 & 78 & 959 & 346 & 752 & 338 & 2760 & 1212 \\
\hline 09.05. & 414 & 53 & 142 & 18 & 908 & 29 & 975 & 62 & 2439 & 162 \\
\hline 10.05. & 1068 & 22 & 152 & 1 & 1127 & 1 & 1333 & 16 & 3680 & 40 \\
\hline 11.05. & 1201 & 9 & 328 & 1 & 2208 & 3 & 1914 & 2 & 5751 & 15 \\
\hline 12.05. & 795 & 5 & 216 & 2 & 894 & 2 & 683 & 3 & 2588 & 12 \\
\hline 13.05. & 28 & 3 & 20 & 0 & 31 & 2 & 13 & 0 & 92 & 5 \\
\hline 14.05. & 7 & 0 & 10 & 0 & 10 & 1 & 17 & 0 & 44 & 1 \\
\hline 15.05. & 117 & 0 & 62 & 0 & 190 & 0 & 116 & 0 & 485 & 0 \\
\hline 16.05. & 2 & 0 & 0 & 0 & 1 & 3 & 2 & 0 & 5 & 3 \\
\hline 17.05. & 1 & 1 & 0 & 0 & 0 & 1 & 0 & 0 & 1 & 2 \\
\hline 18.05. & 11 & 0 & 2 & 0 & 6 & 1 & 6 & 0 & 25 & 1 \\
\hline 19.05. & 34 & 0 & 26 & 0 & 46 & 0 & 46 & 0 & 152 & 0 \\
\hline 20.05. & 16 & 1 & 19 & 0 & 17 & 0 & 16 & 0 & 68 & 1 \\
\hline 21.05. & 22 & 0 & 4 & 0 & 16 & 0 & 6 & 0 & 48 & 0 \\
\hline 22.05. & 4 & 0 & 0 & 0 & 2 & 1 & 2 & 1 & 8 & 2 \\
\hline 23.05. & 0 & 0 & 0 & 0 & 0 & 0 & 0 & 0 & 0 & 0 \\
\hline 24.05. & 0 & 1 & 0 & 2 & 0 & 0 & 0 & 1 & 0 & 4 \\
\hline 25.05. & 0 & 0 & 0 & 0 & 0 & 0 & 0 & 0 & 0 & 0 \\
\hline Total & 5785 & 3766 & 1088 & 1222 & 7467 & 5846 & 7233 & 7196 & 21573 & 18030 \\
\hline & & & & & & & & & & \\
\hline
\end{tabular}

Tab. 3. The number of monthly captures acording to the colour of panel

\begin{tabular}{|c|c|c|c|c|c|c|}
\hline Colour panels & Year & Captures & $\begin{array}{c}\% \text { Of } \\
\text { control }\end{array}$ & $\begin{array}{c}\text { Difference to } \\
\text { control }\end{array}$ & $\begin{array}{c}\text { The semnificance of } \\
\text { difference }\end{array}$ & The Duncan test \\
\hline White & \multirow{4}{*}{2012} & 5785 & 100,0 & 0 & $\mathrm{Mt}$ & $\mathrm{C}$ \\
\hline Blue & & 1088 & 20,4 & -4697 & 000 & A \\
\hline Yellow & & 7467 & 129,1 & 1682 & $* * *$ & $\mathrm{D}$ \\
\hline Green & & 7233 & 125,0 & 1448 & $* *$ & $\mathrm{D}$ \\
\hline White & \multirow{4}{*}{2013} & 3766 & 100,0 & 0 & $\mathrm{Mt}$ & $\mathrm{B}$ \\
\hline Blue & & 1222 & 32,4 & -2544 & 000 & A \\
\hline Yellow & & 5846 & 155,2 & 2080 & $* * *$ & $\mathrm{C}$ \\
\hline Green & & 7196 & 191,1 & 3430 & $* * *$ & $\mathrm{D}$ \\
\hline & & $\begin{array}{r}\text { DL ( } \\
\text { DL ( } \\
\text { DL (p }\end{array}$ & $\begin{array}{l}5 \%) \\
1 \%) \\
0.1 \%) \\
\end{array}$ & $\begin{array}{c}846,45 \\
1160,85 \\
1580,04 \\
\end{array}$ & \multicolumn{2}{|c|}{$\mathrm{DS}=846,49$} \\
\hline
\end{tabular}


between $10-15 \%$; on 8 branches attack frequency was between $5-10 \%$ and on 13 branches frequency was below $5 \%$.

Can by mentioned that every year in mass capturing of adult variant, while reducing attack frequency, it was noted an accentuated decrease of attack intensity (number of mines per leaf was much less).

\section{CONCLUSION}

Mass capture of Monarthropalpus buxi Geoff. adults with colored panels decreased the attack frequency at a rate of about $88 \%$ in 2012 (frequency of infested leaves was $8.61 \%$ compared to $70.78 \%$ in control variant) and $90 \%$ in 2013 (frequency of infested leaves was $7.67 \%$ compared to $77.36 \%$ in the control).

Tab.4. The attack frequency of the Monarthropalpus buxi Geoff. species on Buxus sempervirens L.(mass capturing of adult with colored panels variant, Cluj-Napoca, 2012, 2013)

\begin{tabular}{|c|c|c|c|c|c|c|c|c|}
\hline \multirow{3}{*}{ Sample } & \multirow{2}{*}{\multicolumn{2}{|c|}{ Leaves analysed/plant }} & \multicolumn{4}{|c|}{ Out of which: } & \multirow{2}{*}{\multicolumn{2}{|c|}{ Attack frequency $\%$}} \\
\hline & & & \multicolumn{2}{|c|}{ Healthy leaves } & \multicolumn{2}{|c|}{ Attacked leaves } & & \\
\hline & 2012 & 2013 & 2012 & 2013 & 2012 & 2013 & 2012 & 2013 \\
\hline 1 & 72 & 77 & 66 & 71 & 6 & 6 & 8,33 & 7,79 \\
\hline 2 & 94 & 60 & 83 & 56 & 11 & 4 & 11,70 & 6,67 \\
\hline 3 & 103 & 84 & 96 & 81 & 7 & 3 & 6,80 & 3,57 \\
\hline 4 & 87 & 52 & 82 & 44 & 5 & 8 & 5,75 & 15,38 \\
\hline 5 & 62 & 97 & 55 & 86 & 7 & 11 & 11,29 & 11,34 \\
\hline 6 & 91 & 105 & 79 & 96 & 12 & 9 & 13,19 & 8,57 \\
\hline 7 & 56 & 59 & 51 & 57 & 5 & 2 & 8,93 & 3,39 \\
\hline 8 & 39 & 94 & 37 & 86 & 2 & 8 & 5,13 & 8,51 \\
\hline 9 & 75 & 83 & 74 & 69 & 1 & 14 & 1,33 & 16,87 \\
\hline 10 & 114 & 116 & 106 & 109 & 8 & 7 & 7,02 & 6,03 \\
\hline 11 & 53 & 75 & 50 & 63 & 3 & 12 & 5,66 & 16,00 \\
\hline 12 & 80 & 68 & 66 & 64 & 14 & 4 & 17,50 & 5,88 \\
\hline 13 & 52 & 97 & 51 & 94 & 1 & 3 & 1,92 & 3,09 \\
\hline 14 & 83 & 58 & 76 & 51 & 7 & 7 & 8,43 & 12,07 \\
\hline 15 & 73 & 44 & 64 & 43 & 9 & 1 & 12,33 & 2,27 \\
\hline 16 & 109 & 91 & 99 & 79 & 10 & 12 & 9,17 & 13,19 \\
\hline 17 & 48 & 76 & 41 & 76 & 7 & 0 & 14,58 & 0 \\
\hline 18 & 79 & 52 & 77 & 50 & 2 & 2 & 2,53 & 3,85 \\
\hline 19 & 39 & 99 & 39 & 96 & 0 & 3 & 0 & 3,03 \\
\hline 20 & 31 & 77 & 27 & 69 & 4 & 8 & 12,90 & 10,39 \\
\hline 21 & 63 & 53 & 55 & 52 & 8 & 1 & 12,70 & 1,89 \\
\hline 22 & 77 & 109 & 66 & 102 & 11 & 7 & 14,29 & 6,42 \\
\hline 23 & 94 & 82 & 91 & 79 & 3 & 3 & 3,19 & 3,66 \\
\hline 24 & 53 & 37 & 51 & 37 & 2 & 0 & 3,77 & 0 \\
\hline 25 & 59 & 73 & 53 & 69 & 6 & 4 & 10,17 & 5,48 \\
\hline 26 & 78 & 88 & 65 & 73 & 13 & 15 & 16,66 & 17,05 \\
\hline 27 & 63 & 59 & 54 & 59 & 9 & 0 & 14,29 & 0 \\
\hline 28 & 71 & 98 & 69 & 82 & 2 & 16 & 2,82 & 16,33 \\
\hline 29 & 43 & 75 & 43 & 73 & 0 & 2 & 0 & 2,67 \\
\hline 30 & 39 & 83 & 35 & 77 & 4 & 6 & 10,26 & 7,23 \\
\hline Total & 2080 & 2321 & 1901 & 2143 & 179 & 178 & 8,61 & 7,67 \\
\hline
\end{tabular}


Can by mentioned that every year in mass capturing of adult variant, while reducing attack frequency, it was noted an accentuated decrease of attack intensity (number of mines per leaf was much less).

During two years of using colored panels we have captured 39603 adults (in 2012 there were 21573 capture, and in 2013 we captured 18030).

On color types of the capture statement is as follows: $36.4 \%$ were on green panels; $33.7 \%$ were on yellow panels; $24.1 \%$ were on white panels; $5.8 \%$ were on blue panels.

\section{REFERENCES}

1. Batdorf LR (1994). Boxwood Handbook, American Boxwood Society, Boyce,VA:99.

2. Bena G, Grossoni P, Mori B (1996). Observations on the morpho-anatomical development of the boxwood leaf gall induced by Monarthropalpus buxi (Laboulbene)(Diptera Cecidomyiidae). Journal Advances in Horticultural Science 10(2):99-103.
3. Brewer JW, Skuhravý V, Skuhravý M (1984). Biology, distribution and control of Monarthropalpus buxi (Laboulbène) (Diptera, Cecidomyiidae). Journal Zeitschrift für Angewandte Entomologie 97(2 ):167-175.

4. Coutin R (1991). La cécidomyie du buis. Journal Phytoma 426:55-56.

5. Eustachio G, Raupp MJ (2001). Application of systemic insecticides in relation to boxwood leafminer's life history. Journal of Arboriculture 27(5):255-262.

6. Hrubik PV, Brewer JW (1998). Susceptibility of 10 taxa of boxwood (Buxus ssp.) to attacks of the gall midge Monarthropalpus flavus Schrank, (M. buxi Lab.) (Diptera, Cecidomyiidae) in 8-year experiments. Journal Acta Horticulturae et Regiotecturae 1(2):33-35.

7. Skuhravá M (2005). Species richness of gall midges (Diptera: Cecidomyiidae) in the main biogeographical regions of the world. Acta Societatis Zoologicae Bohemicae 69:277-320.

8. Vamvakas M, Kontodimas DC, Milonas PG (2006). First record of Monarthropalpus buxi in Greece and some data of its phenology. Entomologia Helenica 16:22-26. 


\title{
Amino Acids in Brewer's Yeast Involved in Heavy Metal Biosorption from Waste Water
}

\author{
Andreea STĂNILĂ $\breve{1}^{1}$ Tania MIHĂESCU² \\ ${ }^{1}$ Faculty of Food Science and Technology, University of Agricultural Sciences and Veterinary Medicine, \\ 400372, 3-5 Manastur St., Cluj-Napoca, Romania \\ ${ }^{2}$ Faculty of Agriculture, University of Agricultural Sciences and Veterinary Medicine, 400372, 3-5 \\ Manastur St., Cluj-Napoca, Romania \\ * corresponding author: tania.mihaescu@usamvcluj.ro
}

Bulletin USAMV series Agriculture 72(1)/2015

Print ISSN 1843-5246; Electronic ISSN 1843-5386

DOI 10.15835/buasvmcn-agr: 11172

\begin{abstract}
Yeasts of genera Saccharomyces are efficient biosorbents for heavy metal ions. The aim of this study was to identify if the free amino acids present in brewer yeast are involved in metal biosorption due to their capacity to coordinate metal ions.

As biosorbent was used non-living brewer's yeast type Saccharomices cerevisae at $0.5 \%$ yeast dose. Copper, lead and zinc solution of $1 \mathrm{mg} / \mathrm{L}$ concentrations were prepared using their salts. The experiments were conducted at three $\mathrm{pH}$ level $(3.5 ; 5 ; 6)$. The amino acids were identified by HPLC chromatography and FT-IR spectroscopy. The experiments were conducted by mixing metals solution with yeast and shaken at a constant speed of $120 \mathrm{rpm}$ at $20^{\circ} \mathrm{C}$ for 120 minute. The samples were centrifugated at $2500 \mathrm{rpm}$ for 15 minute and the pellet were analysed for amino acids identification. The amino acids extraction from pellets were performed using two solvent types: $\mathrm{HCl} 0.05 \mathrm{M} /$ ethanol and $\mathrm{HCl} 0.05 \mathrm{M} /$ water. The HPLC analysis was performed using a C-18 column and a mixture of $\mathrm{K}_{2} \mathrm{HPO}_{4} 50 \mathrm{mM} /$ acetonitrile solution as mobile phase in gradient conditions. The FT-IR spectra of samples extracts were recorded with Shimadzu IR-Prestige spectrophotometer.

The amino acids identified by HPLC method were Glu, Arg, Ala, Gly, Lys, Hys, Met, Threo and their profile differs according with extraction solvent used and the $\mathrm{pH}$ of the pellets. Best results were obtained with $\mathrm{HCl}$ / water system and the appropriate $\mathrm{pH}$ for metal biosorption was 6. In the FT-IR spectra information about metal coordination were obtained by comparing the IR amino acids frequencies from control extract with the samples. The presence of shifted absorption band demonstrated the involvement of amino acids by their $\mathrm{NH}_{2}$ and $\mathrm{COOH}$ groups in metals coordination.
\end{abstract}

Keywords: amino acids, biosorption, brewer yeast, heavy metals

\section{INTRODUCTION}

Biosorption can be defined as the selective sequestering of metal soluble species that result in the immobilization of the metals by microbial cells. Biosorption is a process with some unique characteristics. It can effectively sequester dissolved metals from very dilute complex solutions with high efficiency. This makes biosorption an ideal candidate for the treatment of high volume low concentration complex wastewaters $[1,2]$.

The selective sequestering of metal soluble species that result in the immobilization of the metals by microbial cells is defined as biosorption. It refers to physicochemical mechanisms of inactive (i.e. non-metabolic) metal uptake by microbial biomass [3]. Metal sequestering by different parts of the cell can occur via various processes: complexation, chelation, coordination, ion exchange, precipitation, reduction [4, 5]. Immobilization may be the result of more than one mechanism, for example, metal complexation may be followed by metal reduction or metal precipitation.

Metabolically active and inactive cells behave in different ways. Thus inactive microbial cells can 